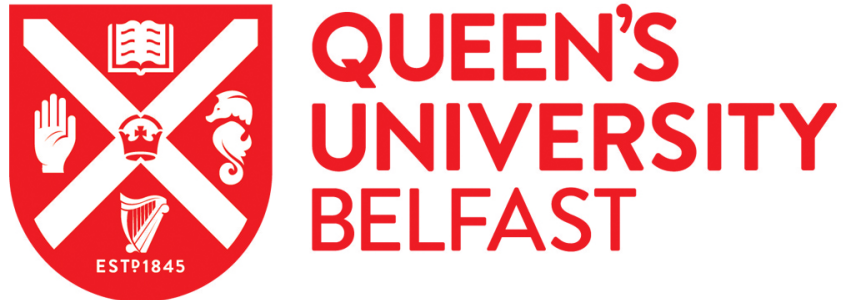

\section{Finding a Scientific Voice: Performing Science, Space and Speech in the Nineteenth Century}

Finnegan, D. A. (2017). Finding a Scientific Voice: Performing Science, Space and Speech in the Nineteenth Century. Transactions of the Institute of British Geographers, 42(2), 192-205. https://doi.org/10.1111/tran.12159

\section{Published in:}

Transactions of the Institute of British Geographers

\section{Document Version:}

Peer reviewed version

Queen's University Belfast - Research Portal:

Link to publication record in Queen's University Belfast Research Portal

\section{Publisher rights}

(C) 2016 Royal Georgraphical Society (with the Institute of British Geographers)

This is the peer reviewed version of the following article:

Finnegan, D. A. (2016), Finding a scientific voice: performing science, space and speech in the 19th century. Transactions of the Institute of British Geographers, which has been published in final form athttp://onlinelibrary.wiley.com/wol1/doi/10.1111/tran.12159/abstract. This article may be used for non-commercial purposes in accordance with Wiley Terms and Conditions for Self-Archiving

\section{General rights}

Copyright for the publications made accessible via the Queen's University Belfast Research Portal is retained by the author(s) and / or other copyright owners and it is a condition of accessing these publications that users recognise and abide by the legal requirements associated with these rights.

Take down policy

The Research Portal is Queen's institutional repository that provides access to Queen's research output. Every effort has been made to ensure that content in the Research Portal does not infringe any person's rights, or applicable UK laws. If you discover content in the Research Portal that you believe breaches copyright or violates any law, please contact openaccess@qub.ac.uk. 


\title{
Finding a scientific voice: performing science, space and speech in the nineteenth century
}

\author{
Diarmid A. Finnegan \\ School of Natural and Built Environment, Queen's University, Belfast, BT7 1NN \\ Email: d.finnegan@qub.ac.uk
}

This is the peer-reviewed version of the following article: Diarmid A. Finnegan, 'Finding an scientific voice: performing science, space and speech in the nineteenth century,' Transactions of the Institute of British Geographers (2017): This article may be used for non-commercial purposes in accordance with Wiley Terms and Conditions for SelfArchiving.

\begin{abstract}
Taking as a point of departure recent scholarly interest in the geographies of spoken communication, this paper situates the cultivation of a scientific voice in a range of nineteenth-century contexts and locations. An examination of two of the century's most celebrated science lecturers, Michael Faraday and Thomas Henry Huxley, offers a basis for more general claims about historical relations between science, speech and space. The paper begins with a survey of the 'ecologies' of public speaking in which advocates of science sought to carve out an effective niche. It then turns to a reconstruction of the varying and variously interpreted assumptions about authoritative and authentic speech that shaped how the platform performances of Faraday and Huxley were constructed, contested and remediated in print. Particular attention is paid to sometimes clashing ideals of vocal performance and paralinguistic communication. This signals an interest in the performative
\end{abstract}


dimensions of science lectures rather more than their specific cognitive content. In exploring these concerns, the paper argues that 'finding a scientific voice' was a fundamentally geographical enterprise driven by attempts to make science resonate with a wider oratorical culture without losing distinctive appeal and special authority.

\section{Key words}

Speech Spaces; Vocal Culture; Science Lectures; Michael Faraday; Thomas Henry Huxley

\section{Introduction}

In an article published towards the end of his career, the celebrated controversialist, biologist and lecturer Thomas Henry Huxley put himself forward as 'an excellent test object of oratory'. During lectures Huxley confessed he had, 'an ineradicable tendency to think of something else'. There had only been a few speakers that could 'delight' Huxley and hold his attention. Chief among them was that 'unsurpassed model of the profound yet popular expositor of science,' Michael Faraday (Huxley 1894b, 5). At the time Huxley wrote those words, his own reputation as a leading orator and science communicator was long established. What has not often been noticed is that Faraday and Huxley's celebrity status as public speakers was tightly linked to a dynamic culture of oratory that flourished during the Victorian period. Scientific expertise was only one factor in their success. Their ability to captivate listening audiences greatly accelerated their rise to fame. This was true even with the acknowledged importance of the printed word in establishing their credentials as authoritative voices in the Victorian public sphere.

This paper examines in detail the oratorical performances of these two leading scientific expositors and casts their careers into a context, in all its flux and diversity, little explored by historical geographers or historians of science. It does this without claiming that 
Faraday and Huxley were, in any strict sense, representative figures. As Lightman (2007b) has shown, to imply that either was typical is to miss the diverse ways in which science was communicated to a range of audiences during the nineteenth century. Both, however, can be studied as individuals who were prominently positioned within oratorical culture and whose platform performances - or, rather, the assumptions and practices that shaped them - can be reconstructed in some detail. They serve, in other words, the paper's larger purpose, which is to construct an argument about the historical geographies of public speech that contributes to work by geographers and others on the spatial practices and situated nature of spoken discourse.

In recent years there has been growing scholarly interest in the geographies of oral communication. This attention has prompted work on the spatialities of legal and scientific speech in historical context (e.g. Finnegan 2011; Keighren 2008; Livingstone 2007; Ogborn 2011a, 2011b; Toal 2012) and studies of talk as-it-happens in a variety of political and social situations (e.g. Kanngieser 2012; Brickell 2013). Notwithstanding the obvious differences between historical and 'real-time' analysis of the practices of speaking and acts of listening, this work shares a concern with the intimate and lively connections between speech and space. Livingstone $(2013,378)$, for example, notes the ways in which speech spaces operate as distinct 'theatres of engagement' governed by different 'codes of behaviour [and] communication conventions'. That is not to say that what is spoken in particular arenas is fully determined by such constraints. As Livingstone and others have argued, 'spatial norms and regulatory regimes' (Valentine et al, 2008, 385) can be subverted as well as reinforced by acts of speaking. Yet even subversive speech remains inescapably informed by the protocols it seeks to unsettle. Speech, like other discursive forms, is both 'reflective' of particular circumstances and 'generative' of novel spaces of communication (Philo 2012, 363) such that 'voice and geography co-create one another' (Kanngieser 2012). 
Another feature of scholarship on the 'geographies of talk' (Laurier 1999) is a concern with aspects of communicative performances not conventionally recorded in text. The importance of prosody (rhythm, intonation, volume) and non-vocal correlates of speech has been examined (on paralanguage, see Kanngieser 2012; on gesture, see Laurier and Philo 2006). Needless to say, these non-verbal aspects of communication are only recoverable in precise detail through exacting ethnographies $-\mathrm{a}$ form of inquiry foreclosed to those interested in speech events in the past. Even so, investigations of the 'historical geography of talk' (Ogborn 2013, 252) can unearth influential assumptions about the relative significance of speech as originally performed. Moreover, detailed descriptions of tone, gesture, volume, pace and other dimensions of the 'total performance' of speaking, formal or otherwise, can provide a rich historical resource for reconstructing influential convictions about how 'live' speech functioned as a cause and consequence of specific social and cultural configurations.

To contribute to this body of work and bring it into conversation with recent scholarship on the cultural history of science this paper offers a study of science lectures in nineteenth-century Britain, approached primarily as vocal performances. Historians of nineteenth-century scientific culture have long taken the lecture seriously as a mode of communication vital to the dissemination of science, and to its growing cultural authority (for examples of earlier work, see Hays 1983 and Inkster 1977; for more recent scholarship, Howard 2004 and Lightman 2007a). This work has not, however, placed lectures within the context of nineteenth-century oratorical or lecture culture. Instead, visual culture has commonly been presented as the obvious nineteenth-century context for making sense of science lectures (e.g. Morus 2006). Given the importance of visual technologies and spectacle and the emphasis placed on sight and seeing in nineteenth-century science, there are good reasons for this. At the same time, however, there are grounds for turning to the oral rather more than the ocular aspects of science lectures. It is argued here that the spoken word, and 
the set of communicative practices associated with it, operated as a powerful medium for expressing and transforming the cultural and social meaning of science.

While this paper concentrates on formal speech events and the more diffuse 'lecture culture' associated with them, it is worth noting that other modes of spoken communication helped to generate and replicate cultures of science during the nineteenth century. As Secord (2007) has demonstrated, the changing role of conversation about scientific subjects can tell us much about shifting appraisals of science in wider culture. In the early nineteenth century, science provided fashionable topics for polite conversation in elite society. Later in the century, scientific subjects became a form of 'shop talk' rather than a topic of interest to a social elite. This change was driven less by alterations in the organisation of scientific knowledge (such as specialisation and professionalization) and more by the shifting norms of conversation particularly in high society. In a similar fashion, it can be argued that the historical geography of the changing significance and function of science lectures in the nineteenth century can only be fully appreciated with reference to the rules and resources that informed cultures of public speech more generally. That this argument can be pursued at the level of lecture performance is one of the possibilities explored by this paper.

As well as surveying largely uncharted territory, attending to the geographies of scientific speech presents an opportunity to build on the productive connections between historical geography and the history of science forged from a common concern with the spatialities of scientific culture (see, for example, Livingstone and Withers 2011). Following Goffman (1981), lectures might be thought of as a form of organized or ritual talk strongly aligned to a circumscribed venue, audience and occasion. Where they are delivered thus has a significant influence on their form, functions and impact. That does not mean, of course, that a lecture performance is fully determined by location and occasion. At the very least, however, the cultural and material co-ordinates of the original performance matter and in 
important ways. Indeed, the spoken word, more perhaps than the printed one, has long been recognized as a profoundly situated or contextual form of communication. None of this is to deny that written or printed texts are not also a matter of rhetorical performance or have their own geographies of production and reception (e.g. Rupke 2000; Secord 2000; Withers and Keighren 2011; Withers and Ogborn 2010). Studies of science and print culture have demonstrated the ways in which the dissemination of science was shaped by, among others, authors, publishers, printers, editors, booksellers and readers - sometimes referred to as a ‘circuit of communication' (following Darnton 1982). However, the 'circuitry' of lecturers, listeners, auditoriums, elocutionists and more has been left under-explored. And if the 'materiality' of printed scientific and geographical texts has been closely scrutinised (e.g. Mayhew 2007), the embodied nature of spoken scientific discourse has received less attention. Of course, the circuits inevitably overlapped and interacted in ways that transformed both (see Hoegaerts 2015; Wright forthcoming). It is nevertheless possible to foreground the clusters of practices - vocal, paralinguistic, ritualistic and inter-medial involved in platform performances in order to fill out accounts of the geographies of communication crucial to the changing public meaning and cultural authority of Victorian science.

To further explore these concerns, the next section situates science lectures within the changing landscape of nineteenth-century oratorical culture. This provides a dynamic backdrop for more detailed accounts of Michael Faraday and Thomas Henry Huxley.

\section{Science lectures and the geography of Victorian oratory}

In Walter Ong's (1974) well-known estimation, the nineteenth century was characterised by a 'heavy residue' of orality, particularly in the form of public speech. The prevalence of oratory has been confirmed by recent scholarship on platform culture (e.g. Hewitt 2002). Joseph 
Meisel (2001, 275), for example, observes that by 1881, 'more people were producing more public speech than during any previous period in British history'. Pace Ong, then, spoken address was not so much a residual oral form than a dominant and near ubiquitous mode of public expression. In an age of reform and religious ferment, the political platform, the courtroom and the pulpit - to name the most obvious - became key spaces of spoken address and crucial sites for enunciating and enacting social transformation. Lectures were a vital sub-set of this explosion of public speech and their popularity and growing diversity made them a significant part of a diffuse and diverse culture of oratory (Hewitt 2012). This significance was not, of course, restricted to Britain. In the United States, for example, the lecture had, if anything, greater prominence and civic importance (Ray 2005). There, the lyceum movement was regarded as a leading instrument in the creation of national identity and a leading agent for promoting a demotic public sphere.

In the midst of a vital landscape of talk, creating a distinctive space for scientific speech presented an abiding challenge to those anxious to harness the power of the spoken word in service of science. Lecturers had to negotiate rhetorical extremes and material challenges to hold the attention of their audiences without compromising their reputation as guardians of scientific truth. Speakers on scientific topics, to attract attention in a crowded culture of speech, had to draw on a range of oratorical techniques without inviting the charge that they were replicating the worst excesses of other types of public speaking. Functioning within a competitive field, lecturing on science had to be sensitive to trends within vocal culture, employing modes of address that connected with audiences but in ways appropriate to subject matter and to ideas about the nature of science as an emerging cultural formation and social ethos.

The search for an appropriate spoken register for science faced not only negative judgements based on notions of inappropriate vocal performances but also had to grapple 
with influential theories about the character and conduct of authentic public speech. Gaillet $(2010,152)$ has pointed to the difficulties of identifying governing assumptions about effective public speaking that cut across different social spaces and rhetorical contexts. An influential trend worth noting, however, was a shift towards prioritising the charisma of the speaker over and against the efficient but colourless verbal transmission of a written text. One driver of this transformation came in the form of the 'elocutionary revolution,' a transAtlantic movement originating in the mid-eighteenth century but which continued to influence conceptions of effective oratory well into the nineteenth century. As Fliegelman $(1993,2)$ describes it, this revolution 'made the credibility of arguments contingent on the emotional credibility of the speaker. Preoccupied with the spectacle of sincerity and an intensified scrutiny of the body as an instrument of expression, the quest for a natural language led paradoxically to a greater theatricalization of public speaking, to a new social dramaturgy, and to a performative understanding of selfhood'. The re-conceptualisation of the lecturer as primarily concerned with the art of 'presence,' rather than with the efficient dispersal of information was fuelled by the rapid expansion in the availability of printed text. The oral transmission of information was no longer the only way to communicate knowledge beyond a small circle of learned elite and this helped to transform the lecture into an artful performance of individual creative 'genius' (Friesen 2011; Clarke 2006). An emphasis on moving as much as instructing an audience presented particular challenges for the science lecturer. Science was widely regarded a form of rational inquiry that restrained rather than inflamed the emotions. Managing the affective dynamics of scientific speech was thus a delicate but crucial task.

Against this backdrop of powerful judgements about what constituted compelling spoken communication, science lecturers had to grapple with a number of urgent questions. Where was the best place to talk about science? What was the appropriate rhetorical register 
for the science lecture? How could science be communicated in a way that captured not just the eye but also commanded concentrated attention and public admiration? Other questions were also equally urgent. Should the science lecturer employ oratorical arts to move as well as instruct the listener? More generally, what was the relationship between science, speech and sentiment?

One answer was to construct spaces deliberately designed to facilitate the production and performance of scientific speech. In the nineteenth century, the lecture theatre became a standard desideratum of scientific institutions and helped advertise science lectures as a distinct and significant civic practice (Forgan 1986). The architecture of the theatres not only displayed the cultural relevance of science but also enabled and ennobled its spoken communication. For all that, only a relatively small proportion of science lectures were delivered in spaces deliberately designed to facilitate scientific speech. Advocates of science as a vital agent for cultural coherence and change had to find ways of communicating in other spaces and in ways that resonated with public expectations about appropriate and compelling speech. Speaking in spaces that were designed for other kinds of vocal or musical performances made keeping scientific speech distinctive without losing an audience's attention a formidable problem.

This was an issue compounded by a rapid expansion in newspaper reportage. The remediation of lectures, theatrical performances and other forms of public entertainment through press reports helped to transmit and transform speech in new and destabilizing ways. The act of transcription itself not only increased the audience of speech events considerably but could also re-work the meaning of lectures through additions or alterations made by a phonographer or editor (for a telling example, see Anderson 1997). Surrounding verbatim accounts of lectures with commentary on the character, body and vocal performance of the speaker further transformed the social and cultural import of speech events. Press reports, in 
other words, became a key actor in the formation of new spaces of scientific speech that were strongly conditioned by a vigorous and heterogeneous culture of attention.

The rise and changing patterns of newspaper reportage, along with the shift towards a speaker's charisma and platform presence, was also closely linked to the emergence of 'celebrity culture'. As John Plunkett has expressed it $(2016,539)$, 'the Victorian period saw the ... mystique of 'celebrity' become an established part of cultural life, percolating into many social and professional arenas'. Public lectures were one important site where celebrity was fashioned, providing as it did occasions for cultivating public intimacy. This presented opportunities as well as pitfalls for the science lecturer. Mobilizing the 'technologies' of celebrity, including that of the body and voice, not only enhanced ticket and book sales but also accelerated the cultural and moral influence of science. At the same time, the dangers of becoming a scientific celebrity had to be faced. Would audiences become more interested in the celebrity than their message? Might an appetite for intimacy threaten a strategic segregation of science from sentiment or public knowledge and private conviction? If public exposure on the platform allowed the moral character of the man of science to be exhibited it also endangered reputations by inviting accusations of superficiality and deliberately engineering mass appeal at the expense of truth seeking and integrity.

The voice of the celebrity science lecturer was also judged according to assumptions about gender and class. By the mid-Victorian period female voices were increasingly heard in mainstream as well as more marginal venues (Hewitt 2002). At the level of the paralinguistic, this could be perceived as an unsettling trend, troubling the presumptive 'manly' tenor and tone of public speech. Working class speakers also challenged the hegemony of a more elite form of oratory informed by classical or otherwise polished rhetoric. The enfranchisement of segments of Britain's male working classes certainly altered judgements 
in various contexts about the character of authentic and authoritative speech (Belchem and Epstein 1997).

In considering in detail two of the nineteenth-century's most celebrated scientific orators, the sections that follow piece together some comparable and contrasting ways in which a 'scientific voice' was formulated, performed and re-mediated through public reaction and press attention. Despite a number of similarities, Faraday and Huxley cultivated a distinct manner of talking about science tailored to the spaces in which they spoke and informed by the politics of gender, social station, character and celebrity. Faraday, to whom I now turn, made a single lecture theatre a laboratory in which to test and exhibit an effective way to give voice to science. Huxley, as will be detailed later, aimed to roam more widely, partly by standing stock-still.

\section{A laboratory for scientific speech: Michael Faraday at the Royal Institution}

Michael Faraday's career as a science lecturer began only a few years after he was apprenticed to Humphry Davy, Professor of Chemistry at the Royal Institution, London. His first lectures were delivered at the City Philosophical Society in 1816. As his scientific career developed at the Royal Institution, initially under the tutelage of Davy, he became heavily involved in organising and delivering lectures there. His growing success and reputation as a lecturer was not only due to his commitment to replicating his own experiments in Institution's lecture theatre. It was also a consequence of his sustained attention to the arts of oratory. As Morus $(1998,21)$ indicates, for Faraday 'public speaking was an art as difficult to master as the art of successfully manipulating the experimental apparatus in the Royal Institution's basement laboratory'. Indeed, the two activities - public speaking and working in the laboratory - were united by a commitment to an experimental method designed to uncover nature's laws. Faraday's remark at the start of his career as a public speaker that he 
'intends making some experiments on [lecturing] soon' (James 1991-2012, vol.1, 62) can be read literally. His experiments with speech were in keeping with his other efforts to comprehend, obey, and put on display nature's laws.

From early in his career, Faraday was alert to the importance of attracting and disciplining the eyes and ears of his audiences. His youthful reflections on lecturing reveal a discriminating sense of the differences and connections between seeing and hearing. The eye, he believed, was superior as a conduit for transmitting truths about the external world. As he put it to Benjamin Abbott, 'I need not point out ... the astonishing disproportion or rather difference in the perceptive powers of the eye and the ear and the facility and clearness with which the first of these organs conveys ideas to the mind' (James 1991-2012, vol. 1, 58). That did not mean, however, that the eye should necessarily be privileged in efforts to communicate the results of scientific research. Indeed, precisely because the ear laboured under a disadvantage it was all the more important to work at vocal performance. But the deportment of the speaking body also mattered. While Faraday suggested that physical action in scientific speech 'does not here bear the importance that it does in other branches of oratory' it was nevertheless essential that the science lecturer 'appear as a body distinct and separate from the things around him' rather than being 'glued to the table or screwed on the floor' (James 1991-2012, vol. 1, 60).

Faraday's views were not simply the product of his own experience of attending science lectures and then performing experiments in speaking. They were also the result of his apprenticeship. His patron, Humphry Davy was widely regarded as a master of the art of scientific exposition and his performances involved careful attention to how he spoke. In preparing, Davy would 'repeat a passage two or three different times to witness the difference of effect of variations in the voice' (Davy 1839, 92). As Jan Golinski (2016) has pointed out, Davy's choice of dress and gestures also played a role in the cultivation of his complex 
lecturing persona. Faraday was no doubt aware of Davy's back-stage rehearsals and the character of his on-stage performances. He was also likely aware of the criticisms levelled at Davy's flamboyant and foppish style. Charges of effeminacy, and of attracting undue female attention, threatened Davy's reputation as a manly lecturer. This may have been one motivating factor in Faraday's adoption of a more serious and less emotionally charged lecturing style. He nevertheless followed Davy in carefully rehearsing his delivery. As with Davy, Faraday honed his lecturing performances and persona to suit the perceived needs of the genteel and middle-class audiences at the Royal Institution. This was a conscious and sustained effort in self-improvement and involved an accumulation of skills that aided Faraday, the son of a blacksmith and, initially, an apprentice bookbinder, in becoming the darling of Royal Institution audiences for several decades (Jenkins 2008).

Whatever Faraday learnt from Davy, it was his relationship with the elocutionist Benjamin Humphrey Smart was the most obvious expression of his commitment to developing a particular style of address. In 1818 Faraday attended Smart's lectures on elocution, delivered in the Royal Institution. In the years that followed, Faraday cultivated his oratorical skills by taking private instruction from Smart. Faraday also paid Smart to attend his lectures to review the merits and demerits of his verbal delivery, a practice he continued until at least 1835 (see James 1991-2012, vol. 2, 246). Faraday also attended to Smart's advice on posture and body language. His notes from Smart's lectures include a detailed summary of Gilbert Austin's system of gestures (Faraday 1818, f. 280). Perhaps most relevant for Faraday's own purposes were the movements Smart recommended for reinforcing descriptive and didactic speech. As Faraday records, before beginning, the speaker should 'bring the body into an erect position for which purpose its weight must be thrown back upon [a] retired foot and the one in advance ... drawn in a little'. This stance, which Smart termed 'the first position,' was one of four that allowed the lecturer to address 
the entire audience without ever 'presenting too flat a front to the hearers' (Faraday 1818, $\mathrm{f}$. 284). The style of address that such poses serviced did not require many deliberate gestures. One exception was the use of the arms and hands to emphasise a particularly important point. Smart's advice, following Austin, was to extend 'the index or fore finger... continually lifting [it] up and down so as to mark every accent with a gentle stroke' (1819 134).

These detailed instructions were not incidental to the image of Faraday as a consummate science lecturer. Charles Turner's portrait [Figure 1], first sketched in 1836 and based on Turner's recollections of Faraday lecturing, suggests that Smart's advice was followed with some exactitude (James 1991-2012, vol. 1, 330). It is also possible that Turner was aware of Smart's system and deliberately painted Faraday in the correct pose. Either way, Faraday's manner became associated with an influential account of how the somatic and the semantic could be effectively aligned while speaking. It also allowed Faraday to produce lecture performances that carefully enacted 'manly' virtues and social standing. Self-control and boldness of speech were witnessed and heard by his audiences. Unlike Humphry Davy (see Golinski 2016), Faraday was not charged with over-stating his social position. A carefully managed tone, comportment and dress helped avoid an impression of excessive social climbing while also demonstrating the kind of improvement thought necessary for someone of 'humble' origins.

Suitable actions and carefully pitched utterances not only helped to consolidate Faraday's reputation. According to Smart, they also enabled auditors to experience emotions that expanded the cultural connotations of scientific speech beyond technical aspects encoded in logical and lucid argumentation. Although clearly 'artificial,' rehearsed gestures (used with, for example, 'restraint or boldness, frequency or intermission' (Smart 1819, 127)) were understood as 'natural signs of inward feeling' $(1819,125)$.

The emotive force of Faraday's perorations in particular were often remarked upon 
and, as Cantor (1991) has noted, frequently struck a hortatory and religious note. This was done, however, in a carefully controlled manner. As the astronomer Charles Pritchard (1868, 121) observed,

on more than one occasion when [Faraday] had been discoursing on the some of the magnificent prearrangements of Divine Providence ... he struggled to repress the emotion which was visibly striving for utterance; and then at the last, with one single far-reaching word, he would just hint at his meaning rather than express it.

Another admirer noted that Faraday's enthusiasm sometimes carried him to the point of ecstasy .... His body ... took motion from his mind; his hair streamed out from his head; his hands were full of nervous action; his light, lithe body seemed to quiver with its eager life. His audience took fire with him, and every face was flushed (Pollock 1870, 294).

Despite this forceful description, there was no suggestion that Faraday had somehow lost control. His body remained an instrument of his manly mind. Such judgements were in harmony with Smart's view, carefully noted by Faraday, that effective oratory galvanizes the passions, winning the full sympathy of auditors. In concluding an address, Smart argued it was often fitting to slow the pace of delivery, lower the tone of voice, and use actions that give the impression that the lecturer's 'whole frame [is] overcome by the feelings that impress upon it' $(1819,145)$.

The advice from Smart that helped engender a kind of scientific pathos was a conscious outworking of a particular philosophy of language. As the instrument of reason, language required the "energies of the tongue, articulation and action, the only immediate interpreters between soul and soul' (Smart 1848, 2). Without the aid of rhetoric, by which Smart meant the 'art of speaking' (Smart 1848, 1), language would remain cold and unpersuasive. Framed and infused by rhetoric, artificial language received 'the warmth, the 
life, the feeling and consequently the persuasiveness of natural language' (Smart 1855, 148). Moreover, to make speech work - to gratify the heart and move the will of listeners - the artificial signs of language and the natural signs embodied in glances, tone, rate of delivery and gestures had to be brought into agreement (Smart 1819).

As well as aid an emotionally charged form of speaking suitable for evoking the sublimity of a scientific account of nature and nature's God, Smart's typology of speech provided Faraday with a kind of map that aided efforts to locate his lectures within an expansive landscape of public speech and performance. In Smart, for example, Faraday had a guide to the tones or looks associated with the explicitly theatrical. While Smart believed that his advice on effective diction and delivery was applicable to both speaking and acting, he pointed to forms of dramatic speech that were akin to 'mimickry' rather than a 'natural' style (Smart 1819, 146). In this sense, Faraday's lectures, with their particular prosodic properties and accompanying gestures, offered an embodiment in sound and movement of the characteristics of speech at once scientific and stimulating.

Smart's instructions for effective verbal communication were not the only influence on Faraday's lecture performances. The material and cultural architecture of the auditorium in which he spoke was also significant. Materially, the lecture theatre of the Royal Institution offered a unique space for cultivating scientific speech. In design terms, it was celebrated for its acoustics as much as its lines of sight. A report published just after it opened praised the sonic properties noting that, when filled with 900 people, 'a whisper may be distinctly heard from one extremity of it to the other' (Thompson 1802, 81). Several decades later, Faraday $(1835,25)$ declared that no other lecture theatre could equal it 'in the facility with which the speaker was heard'. These advantages made speaking with the same ease and style elsewhere as challenging a task as moving and re-enacting the elaborate experiments that accompanied Faraday's most popular lectures. Although Faraday did occasionally speak elsewhere, it was 
the lecture theatre of the Royal Institution that supplied the experimental space for cultivating the vocal qualities thought necessary to communicating a scientific ethos.

In addition to the physical properties of the lecture theatre, its cultural 'architecture' also mattered. This took form in part through explicit protocols that conditioned the content and conduct of verbal performance. The Charter of the Institution (1800) debarred speakers from raising disputatious political or religious matters. While his careful adoption of certain elocutionary techniques helped to evoke particular emotions in his hearers, negotiating the terms of the Charter added to the frisson associated with Faraday's perorations on the evidences of divine providence in nature. With a limit on what words could be spoken, the emotional effect took on greater importance. In more general terms, the expectation that lectures delivered under the auspices of the Royal Institution refrain from promoting partisanship helped align scientific speech with a broader conception of civic discourse that avoided controversy and united different sections of society in the common pursuit of truth. It gave science a distinctly liberal tone but one that required careful management and policing. Placing the Royal Institution in the context of late-Georgian and early-Victorian London, it is clear that this configuration of speech, science and politics was only one of many possibilities. In other venues, an entirely different set of relations between science, politics and religion was forged through lectures governed by contrasting regulatory regimes (Hays 1983; Desmond 1989). Indeed, other Royal Institution lecturers, such as the radical philosophical anatomist Robert Grant, pushed against the grain of the reputation as a place for a respectable scientific discourse that reinforced an existing social order (Barmen 1971; Desmond 1989). Such unsettling talk threw into sharp relief the declared and tacit assumptions of what constituted proprietous speech. Unlike some, Faraday, in his capacity as the Institution's most prolific lecturer (James 2004), conformed with, and consolidated, those assumptions. The theatre of the Royal Institution, as managed and utilized by Faraday, 
reproduced a particular kind of speech space that supplied an influential model that shaped the politics of scientific discourse.

As well as regulating his own and other's performances, Faraday also carefully stagemanaged how they appeared in print. As Frank James (2004) has shown, reports of Friday evening discourses and other lectures delivered by Faraday appeared from the late 1820s in weekly periodicals and newspapers. By the $1850 \mathrm{~s}$, he was sending his lecture notes to Charles Dickens for inclusion, in condensed form, in Household Words (James 2011). For all that, Faraday closely controlled the remediation of talk into text. Typically, the reports provided a concise précis of the lecture and offered brief descriptions of any accompanying experiments. There is some evidence that Faraday's reasons for resisting the full publication of his lectures stemmed from the influence of Smart. In 1859, for example, Faraday wrote to a publisher declining the offer to print verbatim lectures he had recently delivered in the Royal Institution. The printed words, he suggested, would 'fall far behind those in the lecture-room' lacking as they would lack 'the experiments and the vivacity of speaking' (James 1991-2012, vol. 5, 476). Five years later Faraday commented to a government commission on education that 'lectures depend entirely for their value upon the manner in which they are given. It is not the matter, it is not the subject, so much as the man' $(1864,379)$. Faraday's lectures embodied this privileging of vocal performance and, to some degree, he resisted the disruptive and disturbing effects of press reporting.

In sum, then, it can be argued that Faraday's lectures were deliberately located, fixed in place at the Royal Institution and with only limited circulation via printed matter beyond its walls. With Smart's help, Faraday positioned himself with some exactitude within a varied and dynamic topography of public speech. His rootedness was in marked contrast with the rise in peripatetic lecturing, a strategy that had become standard among those committed to increasing the cultural influence of science. The annual meetings of the British Association 
for the Advancement of Science, founded in 1831, were one powerful institutional expression of this. Science was also a standard feature of courses of lectures run by provincial philosophical and scientific societies. This expansion provided an opportunity to use the lecture form as a crucial means for securing a prominent place for science in cultural life. At the same time, taking the science lecture on tour brought significant challenges that shaped its content and, what is of most interest here, character. It also occurred in conjunction with shifting norms and expectations associated with public speaking. Turning our attention to Thomas Henry Huxley provides an opportunity to examine in fuller detail the complex interplay between vocal agency, science and the shifting geographies of lecture culture in the second half of the nineteenth century.

\section{An unmoved mover? The scientific oratory of Thomas Henry Huxley}

Shortly after his clash with Bishop Samuel Wilberforce over Darwin's theory of evolution in Oxford, 1860 Huxley commented to the botanist Joseph Hooker that the experience had, 'changed my opinion as to the practical value of the art of public speaking, and that from that time forth I should carefully cultivate it, and try to leave off hating it' (Huxley 1900, 202). This private remark contrasted with Huxley's reputation as someone who deliberately eschewed oratorical techniques and strategies. Throughout his career as a public speaker, Huxley was regularly portrayed as someone who studiously avoided the 'tricks of oratory' (Anon 1871, 367) and simply laboured hard to speak plainly. His celebrated combination of perspicacity, precision and postural stillness was captured by the Vanity Fair caricaturist, Carlo Pellegrini in 1871. Arms folded, eyes set and feet apart - Huxley pose was 'wonderfully matter of fact' (Anon 1871, 306) [Figure 2].

The caricature of Huxley was a powerful one. It gave, as one admirer of his lectures put it, 'an impression of sincerity, of solid force, of immovability' (Smalley 1895, 521). Of 
course there was in this certain assumptions about manliness, born in part of Huxley's long struggle to secure his own masculine identity and the 'manly' credibility of science as a form of intellectual endeavour (see, for example, White 2003). But Huxley was by no means exceptional in this respect and his approach to lecturing tracked a shift in oratorical culture, particularly as seen in parliamentary address. As Josephine Hoegaerts (2015) has argued, in an era of political reform, some parliamentarians adopted a controlled and less dramatic performance marked by a studied lack of verbal and gestural artistry in order to secure perceptions of authenticity and accessibility. The liberal MP, John Bright, was singled out as a particularly prominent example of this ostensibly new style. His disciplined delivery, giving 'his words force without theatrical gesture,' (Robertson 1883, 243) was judged better adapted for a democratic age. It was also a style more appropriate for the 'new platform' (Belchem and Epstein 1997: 190) that helped underwrite the success of the Bright's populist liberal politics. Tellingly, Huxley admired John Bright's speeches (Ward 1896) and the two celebrated orators were favourably compared (e.g. Youmans 1876). Echoing Bright's chaste style, Huxley adopted a performative strategy associated with political reform, respectability and liberal speech. It was a manner of speaking that contrasted to the more theatrical and bombastic oratory of an earlier generation of gentleman leaders associated with political radicalism (Belchem and Epstein 1997). Huxley’s expressions of affinity with artisanal 'working men' and his lectures to them might be judged in this light. He aimed for a 'classless' form of speech that articulated the inter-class virtues of science and its potential to lead to social reform. Huxley's platform performances thus conformed to a vision of science as a form of restraint in service of the search for natural truth free from the lure of religious fancy or divisive class politics.

As already suggested, Huxley's avoidance of more classical or 'fustian' models of oratorical performance did not mean that he paid no attention to well-worn techniques of 
spoken delivery. This is particularly apparent in his commitment, developed early on in his lecturing career, to extemporaneous speech. The revealing comparison here was the pulpit perhaps more than the political platform. As Robert Ellison (1998) has argued, by the middle of the nineteenth century advice for preachers tended to commend extemporaneous delivery. This guidance was based on presumptions about vivacity of extempore address over and against the bookish coldness of reading. When Huxley (1888) later offered his own tips to public speakers he echoed this advice. In a piece entitled 'how to be an orator', Huxley emphasised the importance of writing out a lecture in full but jettisoning the script during delivery. The careful preparation would assist the lecturer resist the 'strange intoxication' produced by 'the breathless stillness of a host of absorbed listeners' $(1888,2)$. But discarding the text and re-clothing the prepared thoughts in new ways was also vital. As Huxley confessed to an admirer, the 'stimulus' of an audience often produced 'better words and phrases than I have thought of at my desk' (Franklin 1910, 223).

This commitment to extemporaneous speech was partly motivated by his estimation of the value of science lectures. Contrary to what might have been thought on account of his reputation for communicating hard facts and clear conceptions, Huxley (1894a, 5) believed that the 'intellectual value' of lectures was severely limited. It was fortunate, then, that 'the living voice has an influence over human action altogether independent of the intellectual worth of that which it utters'. Even if the arguments made were entirely lost on the listener, the spoken word could awaken 'a sympathy for abstract truth' $(1894 a, 6)$. This view was not one that Huxley held only at the end of his career. He expressed similar sentiments at the outset. Writing to John Tyndall in 1854, he commented that the 'secret' of Michael Faraday's success was an ability to convince his audience that they had grasped his meaning even if 'only a tithe ... really understand him' (Huxley 1900, 124). 
The emphasis on creating an impression of comprehension or stimulating an emotional affinity to scientific truth not yet understood was tied to Huxley's understanding of moral action and human volition. While the laws of human conduct could be determined by science, persuading people to act in accordance with them was 'quite beyond mere science' (Huxley 1870,11 ). The desire to obey a moral code was, in Huxley's estimation, a key element of 'all that has any unchangeable reality in religion'. It was, therefore, 'religious feeling,' rather than scientific knowledge that supplied the 'essential basis for conduct' (1870, 11). Part of the appeal of an extempore delivery was the emotional connection it was thought to generate between speaker and audience. It gave the appearance of spontaneous invention, of an immediate connection with the subject under consideration and acted as a stimulus to action informed by a scientific search for moral truth. This might be understood as continuous with, rather than a break from, the vision of science projected by Faraday's rather different vocal performances. While Huxley rejected the specific theological associations of Faraday's vision, he embraced science as a handmaiden to a fundamentally religious sensibility, albeit one free from dogmatic content.

Huxley's apparent disdain for oratorical technique calls for careful qualification. His 'matter of fact' posture, prose and prosody, themselves a carefully cultivated 'technique' of speaking, were invested with emotional meaning. By his own account, Huxley's rhetorical performances interpellated a passion for 'passionless' truth-seeking from his hearers. This was evident, for example, in the peroration to a lecture Huxley delivered in New York in September 1876 at the close of his tour of the United States. Huxley's concluding remarks at the end of a series of three lectures on evolution, summoned a particular response from his audience.

I shall rejoice ... if I have thus convinced you that this great question that we are discussing is not one to be dealt with by rhetorical flourishes or by loose and 
superficial talk, but that it requires the keenest attention of the trained intellect and the patience of the most accurate observer (Anon 1876d, 1).

Reportedly, this declaration was delivered 'with much feeling' (Anon 1876d, 1) and was subjoined with fulsome praise of the audience's evident powers of concentration, itself a kind of emotional reserve and affective state. As reported, the peroration moved the audience, and anticipated Huxley's own desired response. It enacted, and appealed for, a strongly felt sense of gravity and moral profundity and a concomitant joy in the embrace of Huxley's vision of a scientific citizenry.

A closer examination of the prosodic character of Huxley's lecturing style further cements his commitment to stimulating as much as controlling or cancelling the emotions. According to a number of descriptions, Huxley spoke in 'low tones,' and with a clear and measured diction (e.g. Anon 1871a; Anon 1876d; Smalley 1895). Speaking in a lower register no doubt reflected Huxley's natural range but it also facilitated the production of a particular emotional atmosphere, one that was serious and sombre. This, at least, was the lesson proposed by one influential elocution manual - in print throughout the second half of the nineteenth century and widely consulted on both sides of the Atlantic - which noted that 'low notes' were the 'natural language of grave emotions, such as accompany deeply serious and impressive thoughts' (Russell 1845, 186). As well as registering the seriousness of scientific talk, Huxley's bass notes rendered his speech incontrovertibly male. The slow tempo and precise diction of Huxley's lectures added to the overall effect and helped to express a scientific sensibility associated with precision and self-discipline. Huxley pace of delivery - one reporter recorded it at 120 words per minute (Anon 1876b, 8) - encouraged hearers to take careful measure of his 'manly' words.

In these terms, Huxley successfully cultivated a vocal style that embodied his own sense of what scientific lectures could accomplish and helped to manufacture a particular 
kind of scientific speech space replicable in different venues. This is not to suggest that Huxley thereby overcame the 'resistance' encountered in different venues and spaces. In many respects, his efforts to find a stable and portable style was a product of, rather than a victory over, the material and imagined geographies of public speech. It also needs to be noted that Huxley, despite his celebrated reputation, was not always as successful a speaker as his admirers supposed. Voice projection in particular caused Huxley some serious difficulty. If Faraday could rely on the superb acoustics of the Royal Institution's lecture theatre, Huxley had to project his voice in larger auditoria not always designed with speech in mind. A number of reports of lectures delivered by Huxley across the span of his career suggest that this was compounded by a rather weak voice. Joseph Hooker (1860), in a letter to Charles Darwin written just after Huxley crossed swords with Samuel Wilberforce in 1860, commented that Huxley 'could not throw his voice over so large assembly or command the audience'. This vocal weakness was also noted near the end of his career. One report of a lecture delivered in 1893 observed that most of the audience 'heard with difficulty' and 'many hardly heard at all' (Anon 1893, 596). On that occasion, the elderly Huxley had been recovering from a throat infection (Jensen 1991). But the two struggles to be heard in Oxford were bookends to a career-long battle to speak with adequate volume. This was not just about the practical difficultly of being heard. It was also about securing and maintaining a reputation for speaking with manly resolve. A weak voice suggested a lack of conviction. This was made apparent in speech manuals and in press reports of prominent public speakers (Hoegaerts 2015). It was a view shared by one of Britain's most celebrated and controversial evangelical orators, Charles Haddon Spurgeon (Ellison 1998). In a typically forthright declaration, Spurgeon $(1875,122)$ insisted that 'modesty should lead a voiceless man to give place to others who are more fitted to work of proclaiming the messages of the King'. It was perhaps the elevation of this kind of 'muscular' speaking that encouraged George Smalley 
$(1895,521)$ to observe that while Huxley's voice was 'rather deep' and 'low' it was 'always sonorous and full'. When Huxley lectured, he 'was masculine in everything. Look, gesture, speech' $(1895,521)$.

More generally, given the varied expectations among audiences, it is not surprising that Huxley's scientific oratory was not always well received. This was particularly true of his reception in New York at the end of his 1876 tour of the United States. Perhaps more than in Britain, American audiences could be highly critical of a speaker's performance. This was due in part to the significance invested in political speech making and to the value placed on a vibrant 'democratic' lecture culture (Ray 2005; Wright forthcoming). It was also related to the venue in which Huxley spoke - Chickering Hall. The auditorium, a new addition, was part of the entertainment district centred on Union Square. Designed as a concert hall, it was a test ground for judging the success of various vocal performances - whether musical or oratorical.

Whatever regional and local factors were at play, Huxley's lectures were subject to sharp criticism. One report of the first of three lectures pictured Huxley as a man whose 'mind had overtaxed his body' and whose 'air and address' resembled that 'of a not very well-fed evangelical clergyman' (Anon, 1876c, 6). These remarks threatened to undermine Huxley's manly character. Other reports compared Huxley not to an emaciated and effeminate preacher but to a lawyer addressing 'a bench of judges on an obstruse point of law'. He may have been comprehensible but 'he did not fascinate' (Anon 1876e, 2). Reports of his second lecture suggested a yet greater failure to connect with his audience. A columnist in the New York Sun dismissed it as 'tedious, rudimentary and almost inaudible,' (Anon 1876f, 3) while the New York Herald compared the experience of hearing Huxley to 'swallowing a bushel of brick dust' (Anon 1876g, 3). In these accounts, Huxley was pictured as a boring professional pedagogue, a portrait Huxley must surely have found deeply 
irritating. Huxley's lecturing performances aimed at dissolving any association between science and a narrow professionalism. Science, after all, was being presented as the foundation for social betterment, a profoundly moral endeavour rather than a merely technical specialism.

Diverging appraisals of Huxley's lectures were not only tied to the semiotics of vocal performance. His rise to celebrity status as a speaker meant that lectures by Huxley attracted a significant amount of 'social fuss' (Goffman 1981, 168) that framed them as significant public events. For some of Huxley's lectures, this was deliberately encouraged to add weight to his words. On those occasions, what the lectures meant in intellectual or moral terms was generated in part by the ceremonial rituals that accompanied them. There was also the possibility that the ceremonial framing could divert attention away from content and the 'textual self' of the lecturer to the ambient meanings of the total event.

One example was Huxley’s inaugural lecture at Johns Hopkins University delivered on 12 September 1876 . Carefully stage managed by the organiser, the University's newly appointed President, Daniel Gilman, it was advertised as a kind of unofficial commencement address. The content of Huxley's lecture, concerned with educational principles appropriate to the modern university, was largely over-shadowed by local controversy over how the event had been ritually framed. One common complaint was the lack of public prayers, a rite considered by some a non-negotiable feature of any formal opening of a public institution. To some, it was less what Huxley said or how he said it that mattered on that occasion. Rather, it was what was omitted from the ceremonial 'frame' that rendered the entire speech event controversial.

Huxley's reception and his reputation were undoubtedly shaped, then, both by varying estimations of the meaning of certain modes and ways of speaking and by the civic ceremonies that located his speech within particular institutional or political frames. All of 
this was reinforced and reworked by one of the most powerful forces that informed the character and legacies of Huxley's spoken discourse, the press. Unlike Faraday, who was able to closely monitor how lectures delivered at the Royal Institution were re-mediated in print, Huxley faced insurmountable difficulties in attempts to control the press. His lecturing career coincided with the rise of the regional newspaper as a 'civic Hansard' (Hewitt 2002, 11) that reported lectures in sometimes dense detail. Huxley's mobility and his growing celebrity meant that controlling his image, and his words, as they appeared in the press became at once imperative and intractable. That he took this take seriously is not in question. To give just one example, when Huxley delivered a particularly controversial address during the Belfast meeting of the British Association for the Advancement of Science in 1874 he visited the offices of a local newspaper late at night and spent two hours reading and correcting the report that would appear in its pages the next day (Huxley 1900, 446).

Taken in the round, what emerges from this analysis is Huxley's self-conscious use of oratorical techniques to move an audience, whether immediate or 'virtual'. He aimed to make them positively feel as if they were participants in a great scientific quest for 'Truth'. Given the quasi-religious nature of this endeavour, it might be appropriate to describe Huxley as a kind of 'unmoved mover'. Like Faraday, then, he cultivated a stance and a style of address that give the impression of an unwavering and dispassionate commitment to science which, at the same time, stirred an emotional response in his audiences. But unlike Faraday, he was also an 'unmoved mover' in another sense. By fixing his posture and prosody, he aimed to transition efficiently between different venues and social situations without altering his general message about science as the vehicle for social and moral improvement. That did not mean that his vocal performances were everywhere judged successful or everywhere comprehended in the same way, floating free from the contexts that gave them meaning and significance. On the contrary, his manner could be as much an obstacle to public approval as 
his message. In that light, the geography of his scientific oratory might be approached both as a product of Huxley's desire to smooth the effects of material and cultural difference and in terms of the often starkly different assessments of his oral performances across and within particular locations, not least as remediated in print.

\section{Conclusion}

This paper has sought to take seriously science lectures as a kind of total performance conditioned by, and generative of, social and cultural conventions of public speech. In part due to its historical focus, the main purpose of this paper has not been to reconstruct live performances. Rather, it has aimed to excavate and examine a number of influential assumptions about the relations between vocal action, oratorical culture and scientific lectures. In this qualified sense, the paper has worked towards a phonological geography of scientific speech. It has retrieved efforts to make science resonate with widely shared convictions about vocal authority and authenticity while also marking it out as a distinctive, and distinctively authoritative, form of public address.

This was a fundamentally geographical enterprise. Making science, and the man of science, sound and look right meant positioning scientific speech within lecture culture and tailoring it to specific material and cultural locations. This included working at the vocal and non-vocal aspects of spoken communication. Both Michael Faraday and Thomas Henry Huxley cultivated a manner of speaking, with accompanying postures, gestures and facial expressions, to convey a scientific ethos that meshed with the message they were attempting to communicate. In Huxley's case in particular, this invited contrasting evaluations from hearers, not least newspaper reporters. Whether or not the manner and message operated in harmony was in the eye and ear of the auditor or reporter. For a number of commentators, Huxley's platform performances failed to harmonise non-linguistic and linguistic elements 
and communicated various mixed messages. Faraday who remained in place, lecturing only in the Royal Institution and carefully filtering how his performances were reported beyond its walls, generally avoided this kind of critique.

One consequence of attending to convictions about the paralinguistic aspects of scientific speech is that the paper has less to say about the historical geographies of science understood as an exercise in spatialising or situating the production and adjudication of particular scientific claims. Here the emphasis, following the actors involved, has been on the production and varied dissemination of 'science' as a certain kind of ethos or mythos and on the emergence of the science lecturer as particular kind of persona, even celebrity, engendered through encounters with 'live talk'. Because neither Faraday nor Huxley can be taken as representative figures, except with careful qualification, it is not possible to offer more than provisional suggestions about what the similarities and differences between them might tell us about larger changes in the historical geographies of science communication, and of scientific culture, during the nineteenth century.

It is nevertheless possible to point to shifts in the performance of scientific speech that can be read as symptoms of changes that had wider reach and a more distributed influence that the individual speech event. Here, following Secord's (2007) example, I would foreground evidence of pressures coming from the norms and assumptions of cultures of public speech rather more than 'internal' influences that emerged from changes in the organisation of scientific culture. Faraday consciously cultivated vocal and gestural actions in one venue in order to enact a form of speaking suitable for polite, chaste but emotionally resonant scientific speech. This helped to reinforce science as a cultured and theologically meaningful form of knowledge and facilitated Faraday's efforts to negotiate the social and gendered norms of his cultural location. Huxley, in contrast, operated with an ideal of eloquence that tended to denigrate formal training in the arts of oratory and underlined the 
importance of 'unadorned' or 'plain' speaking. This, whether consciously or not, tracked a wider trend in political and pulpit culture that disparaged formulaic gestures and scripted performances even while quietly co-opting certain communicative techniques and vocal registers. In doing so, Huxley faced the challenge of appealing to different social groups and projecting a 'manly' posture and vocal performance.

In making these arguments, the paper has offered an analysis of science in public culture that builds on what Livingstone (2007) has termed the 'hermeneutic dimensions of speech spaces'. By looking closely at the non-lexical components of scientific talk, I have tried to sketch out the difference speaking about science made, understood as a distinctive, if never isolated, performative act. This is to push towards recovering not just the geographies of spoken argumentation but also of paralinguistic communication. One challenge for this kind of work, as Livingstone (2007) underlines, is determining what difference speech qua speech made to how science and its wider cultural meanings were articulated or debated within contrasting interlocutory regimes. I have tried to address that by paying limited attention to the cognitive content of science lectures and examining instead prevailing presumptions about performance on the lecture platform.

Needless to say, much remains to be done both with respect to detailing further the geographies of science communication in the nineteenth century and in terms of exploring more generally the spatialities of vocal actions and interactions. That this should not be restricted to lectures and other more formal or conventional modes of spoken communication goes without saying. There is doubtless more to know about the historical geographies of talk more generally and such research might help examine afresh an illimitable range of knowledge cultures. At the same time, it is important not to neglect forms of speech often assumed to be more artificial and less effectual and influential. Lectures have long been subject to pedagogical critique and it is hard to recover their status and significance or 
appreciate the investment made by lecturers to acquire and deploy oratorical skills in the nineteenth century. There was (and, one could argue, is) no principled reason to assume in advance that 'spontaneous,' informal or un-rehearsed speech provided a communicative practice more revealing of micro-politics, subjectivities or even effective exchange of information or emotion. There are good reasons to suppose that, during the nineteenth century, lectures, understood in terms of ritualized oral performance, powerfully supported certain conceptions of science and its cultural, even metaphysical, import. Whether that conclusion applies to different types of vocal communication in other times and places is a subject worthy of exploration.

\section{References}

Anderson O 1997 Hansard's hazards: an illustration from recent interpretations of the Married Woman's Property Law and the 1857 Divorce Act English Historical Review 112 $1202-1215$

Anon 1871a Men of the Day, No. 19 Vanity Fair 28 January

Anon 1871b Professor Huxley The Sphinx 3367

Anon 1875 Private view of Chickering Hall Sunday Mercury 14 November 4 Anon 1876a Professor Huxley New York Herald 13 September 10 Anon 1876a Huxley at Baltimore New York Tribune 13 September 8 Anon 1876c Prof Huxley's first lecture New York Herald 19 September 6 Anon 1876d Evidences of evolution New York Tribune 23 September 1 Anon 1876eProf Huxley's first lecture The Sun 19 September 2 Anon 1876f Huxley's second lecture The Sun 21 September 3 Anon 1876g Professor Huxley New York Herald 21 September 3 Anon 1893 Professor Huxley at Oxford The Speaker 7596 
Belchem J and Epstein J 1997 The nineteenth-century gentleman leader revisited Social History 22 174-193

Berman M 1978 Social Change and Scientific Organization: The Royal Institution, 1799 1844 Heinemann Educational Books, London

Brickell K 2013 Towards geographies of speech: proverbial utterances of home in contemporary Vietnam Transactions of the Institute of British Geographers 38 207-220 Cantor G 1991 Educating the judgement: Faraday as a lecturer Bulletin for the History of Chemistry $1128-36$

Clarke W 2006 Academic Charisma and the Origins of the Research University University of Chicago Press, Chicago

Darnton R 1982 What is the history of books? Daedalus 111 65-83

Davy, J 1839 The Collected Works of Humphry Davy: Vol 1 Memoirs of His Life Smith Elder and Co., London

Desmond A 1989 The Politics of Evolution: Morphology, Medicine and Reform in Radical London University of Chicago Press, Chicago

Ellison R H 1998 The Victorian Pulpit Susquehanna University Press, Selinsgrove Faraday M 1818 Common Place Book 2 vols, unpublished MS, Institution of Engineering and Technology Archive

Faraday M 1835 in Report from Select Committee on the Ventilation of the Houses of Parliament (583) XVIII.25.

Faraday M 1860 A Course of Six Lectures on the Various Forces of Matter Richard Griffin and Company, London

Faraday M 1864 in Report of Her Majesty's Commissioners Appointed to Inquire into the Revenues and Management of Certain Colleges and Schools (3288) vol. 4 
Finnegan D A 2011 Placing science in an age of oratory: spaces of scientific speech in mid-

Victorian Edinburgh in Livingstone $\mathbf{D} \mathbf{N}$ and Withers $\mathbf{C} \mathbf{W} \mathbf{J}$ eds Geographies of

Nineteenth-Century Science University of Chicago Press, Chicago 153-77

Fliegelman J 1993 Declaring Independence: Jefferson, Natural Language and the Culture of Performance Stanford University Press, Stanford

Franklin F 1910 The Life of Daniel Coit Gilman Dodd, Mead and Company, New York

Friesen N 2011 The lecture as a transmedial pedagogical form: a historical analysis

Educational Researcher 40 95-102

Forgan S 1986 Context, image and function: a preliminary enquiry into the architecture of scientific societies British Journal for the History of Science 19 86-113

Gaillet L L 2010 The nineteenth century in Gaillet L L ed The Present State of Scholarship in the History of Rhetoric University of Missouri, Columbia 152-184

Goffman E 1981 Forms of Talk Oxford, Blackwell

Golinski J 2016 The Experimental Self: Humphry Davy and the Making of a Man of Science University of Chicago Press, Chicago

Hays J N 1983 The London lecturing empire, 1800-50 in Inkster I and Morrell J eds Metropolis and Province: Science in British Culture, 1780-1850 University of Pennsylvania Press, Philadelphia 91-119

Hewitt M 2002 Aspects of platform culture in nineteenth-century Britain Nineteenth-Century Prose 29 1-32

Hewitt M 2012 Beyond scientific spectacle: image and word in nineteenth-century popular lecturing in Kember J Plunkett J and Sullivan J A eds Popular Exhibitions, Science and Showmanship, 1840-1910 79-96

Hoegaerts J 2015 Speaking like intelligent men: vocal articulations of authority and identity in the House of Commons in the nineteenth century Radical History Review 121 123-144 
Hooker J 1860 Letter to C. Darwin, 2 July 1860, Darwin Correspondence Project, Letter no. 2852, accessed on 26 February 2016, http://www.darwinproject.ac.uk/DCP-LETT-2852

Howard J 2004 'Physics and fashion': John Tyndall and his audiences in mid-Victorian Britain Studies in the History and Philosophy of Science Part A 35 729-758

Huxley L 1900 Life and Letters of Thomas Henry Huxley Vol. 1 Macmillan, London

Huxley T H 1870 The school boards: what they can do, and what they may do Contemporary Review 16 1-15

Huxley T H 1888 How to become an orator Pall Mall Gazette 24 October 1-2

Huxley T H 1894a Discourses Biological and Geological Macmillian, London

Huxley T H 1894b John Tyndall Nineteenth Century 35 1-11

Inkster I 1980 The public lecture as an instrument of science education for adults: the case of Great Britain, c. 1750-1850 Pedagogica Historica 20 80-107

James F A J L ed 1991-2012 Correspondence of Michael Faraday 6 vols Institution of Electrical Engineers, London

James F A J L 2004 Reporting Royal Institution lectures, 1826-1867 in Cantor G and Shuttleworth S Science Serialized: Representations of the Sciences in Nineteenth-Century Periodicals MIT Press, Cambridge, Mass. 67-80

James F A J L 2011 Introduction in Faraday M Chemical History of a Candle Sesquicentenary Edition Oxford University Press, Oxford xiii-xlii Jenkins A 2008 Michael Faraday's Mental Exercises: An Artisan Essay Circle in Regency London Liverpool University Press, Liverpool

Jensen J V 1991 Thomas Henry Huxley: Communicating for Science University of Delaware Press, Newark

Johnson N 1991 Nineteenth-Century Rhetoric in North America Southern Illinois University Press, Carbondale 
Jones B 1870 The Life and Letters of Faraday Longmans, Green and Company, London Kanngieser A 2012 A sonic geography of voice: Towards an affective politics Progress in Human Geography 36 336-353

Keighren I M 2008 Giving voice to geography: Popular lectures and the diffusion of knowledge Scottish Geographical Journal 124 198-203

Laurier E 1999 Geographies of talk: 'Max left a message for you' Area 31 36-46

Laurier E and Philo C 2006 Cold shoulders and napkins handed: gestures of responsibility Transactions of the Institute of British Geographers 31 193-207

Lightman B 2007a Lecturing in the spatial economy of science in Lightman B and Fyfe A Science in the Marketplace University of Chicago Press, Chicago 97-132

Lightman B 2007b Victorian Popularizers of Science University of Chicago Press, Chicago Livingstone D N 2007 Science, site and speech: scientific knowledge and the spaces of rhetoric History of the Human Sciences 20 71-98

Livingstone D N 2013 Science wars in Johnson NC Schein RC and Winders J eds The Wiley-Blackwell Companion to Cultural Geography Wiley-Blackwell, Oxford 371-383 Livingstone D N and Withers C W J 2011 Geographies of Nineteenth-Century Science University of Chicago Press, Chicago

Mayhew R J 2007 Materialist hermeneutics, textuality and the history of geography: print spaces in British geography, c.1500-1900 Journal of Historical Geography 33 466-488 Meisel J S 2001 Public Speech and the Culture of Public Life in the Age of Gladstone Columbia University Press, New York.

Morus I 1998 Frankenstein's Children: Electricity, Exhibition, and Experiment in EarlyNineteenth-Century London Princeton University Press, Princeton Morus I 2006 Seeing and believing science Isis 97 101-110 
Ogborn M 2011a The power of speech: orality, oaths and evidence in the British Atlantic world, 1650-1800 Transactions of the Institute of British Geographers 36 109-125

Ogborn M 2011b A war of words: speech, script and print in the Maroon War of 1795-6 Journal of Historical Geography 37 203-215

Ogborn M 2013 Talking plants: botany and speech in Eighteenth-Century Jamaica History of Science 51 251-282

Ong W J 1974 Agonistic structures in academia: past to present Daedulus 103 229-238.

Philo C 2012 Discursive life in Del Casino V C Thomas M E Cloke P and Panelli R eds Companion of Social Geography Wiley Blackwell, London 362-384

Plunkett J 2016 Celebrity culture in eds Oxford Handbook of Victorian Literary Culture Oxford University Press, Oxford 539-560

Pollock J 1870 Michael Faraday St Paul's Magazine 6 292-303

Pritchard C 1868 Analogies in the Progress of Nature and Grace Deighton, Bell, and Co., Cambridge

Ray A G 2005 The Lyceum and Public Culture in the Nineteenth-Century United States Michigan State University Press, East Lansing.

Robertson W The Life and Times of Right Hon. John Bright Cassell and Company, London 1883

Royal Institution 1800 The Prospectus, Charter, Ordinances and Bye-Laws of the Royal Institution of Great Britain Bulmer and Co., London.

Rupke N 2000 Translation studies in the history of science: the example of Vestiges British Journal for the History of Science 33 209-222

Secord J 2000 Victorian Sensation: The Extraordinary Publication, Reception, and Secret Authorship of Vestiges of the Natural History of Creation University of Chicago Press, Chicago 
Secord J 2007 How scientific conversation became shop talk Transactions of the Royal Historical Society 17 129-156

Smalley G W 1895 Mr Huxley Scribner's Magazine 18 514-524

Smart B H 1819 The Theory of Elocution John Richardson, London

Smart B H 1848 A Manual of Rhetoric Longman, Brown Green and Longmans, London Smart B H 1855 Thought and Language Longman, Brown Green and Longmans, London

Thompson B 1802 The Royal Institution of Great Britain Philosophical Magazine 13 80-85

Thompson S P 1898 Michael Faraday: His Life and Work Cassell and Company, London Toal C 2012 Preaching at the British Association for the Advancement of Science British Journal for the History of Science 45 75-95

Valentine G Sporton D and Nielsen K B 2008 Language use on the move: sites of encounter, identities and belonging Transactions of the Institute of British Geographers 33 $376-387$

Ward W 1896 Thomas Henry Huxley: a reminiscence Nineteenth Century 40 274-292

White P 2003 Thomas Huxley: Making the "Man of Science" Cambridge University Press, Cambridge

Wright T F forthcoming Lecturing the Atlantic: Speech, Print and an Anglo-American Commons, 1830-1870 Oxford University Press, New York

Youmans E L 1876 Prof. Huxley Popular Science Monthly 9622 